\title{
A global gravity model for air passenger demand between city pairs and future interurban air mobility markets identification
}

\author{
Kristin Becker ${ }^{1}$ \\ Student, TUHH Institute of Air Transportation Systems, Blohmstraße 20, Hamburg, 21079, Germany \\ Ivan Terekhov ${ }^{2}$, Malte Nikla $\beta^{2}$, Volker Gollnick ${ }^{3}$ \\ German Aerospace Center (DLR), Blohmstraße 20, Hamburg, 21079, Germany
}

\begin{abstract}
With respect to the growing urbanization and subsequently increasing traffic in urban areas this paper presents future potential markets worldwide for interurban air mobility up to $300 \mathrm{~km}$. For this analysis a gravity model is developed to forecast interurban air passenger demand for 2042 between 4435 settlements worldwide based on socio-economic factors. The results of the study provide a list of potential markets for UAM implementation.
\end{abstract}

\section{Nomenclature}

$\begin{array}{ll}\text { GDP } & =\text { Gross Domestic Product } \\ P P P & =\text { Purchasing Power Parity } \\ \text { UAM } & =\text { Urban Air Mobility } \\ V T O L & =\text { Vertical Take-off and Landing }\end{array}$

\section{Introduction}

The concentration of population in urban regions is steadily increasing. According to the UN [1], in 2050 about 70 $\%$ of the global population will live in urban areas and the number of cities with more than 10 million inhabitants will increase significantly.

Urban mobility is indispensable for people as it is an important promoter for employment, trade, and creativity. Driven by converging social and technological trends, numbers and varieties of mobility will increase concurrently across multiple borders and spatial scales (urban, regional, and international). However, urban space is limited. Already today, urban transportation systems barely cope with the ever-growing traffic flows and have almost reached their limits or are close to breaking down [2]. In some cities people spend millions of hours yearly on roads for the everyday commute [3]. In Los Angeles, for instance, each person loses 102 hours on average in traffic jams per year [4]. As ongoing urbanization increases demand and traffic volume continuously, the daily commute of more and more people will further increase. Thus, it is expected that the distance traveled in cities will be tripled [5]. Congested traffic not only impacts the effective lifetime but also as the disease or disability burden in populations due to air pollution, emissions, noise, and accidents. It is precisely the emerging and rapidly growing cities that have to deal with these issues. In the Indian city of Pune (India), for example, air pollution has increased by 35 per cent since 2010, with traffic as the main source of emissions [6].

Due to limited space, it is challenging to improve urban transportation by conventional systems, e.g. new roads. Thus, innovative and sustainable concepts are needed to improve the actual urban mobility. A promising future urban transportation concept is vertical mobility. By using the third dimension, Urban Air Mobility (UAM) will enhance the transport capacity of a city.

\footnotetext{
${ }^{1}$ Student, TUHH Institute of Air Transportation Systems

${ }^{2}$ Research Associate DLR Air Transportation Systems

${ }^{3}$ Head of the DLR Air Transportation Systems DLR Air Transportation Systems
} 
Since UAM is still an innovative concept there are some challenges regarding the path to the market [3]. In addition, some studies refer to certification and law issues as well as social acceptance as additional requirements for vertical mobility ecosystem [4].

Nevertheless, it is necessary to determine the potential markets and demand for UAM worldwide. The investigation of the worldwide UAM demand is important for UAM-providers and for manufacturers to estimate the size of the UAM market. This paper investigates potential markets worldwide for UAM implementation in the future. This analysis is based on a global gravity model and additional assumptions regarding potential markets.

\section{Literature review}

\section{A. Urban Air Mobility}

Since modern technologies have reached a particular level, a number of companies started to work on VTOL (vertical take-off and landing) vehicles for UAM. For instance, two German startups developed an all-electric VTOL with two and five seats [31], [33]. Airbus developed the first self-piloted electric VTOL Vahana $\mathrm{A}^{3}$ [7]. Embraer and Uber plan to develop a 4-person VTOL [8]. Due to technical requirements VTOLs are designed for commuter traffic, short hauls, and areas with insufficient infrastructure or reachability within cities as well as between them.

Fly Blade and Airbus Helicopters are cooperating to make UAM affordable for public. Fly Blade already provides on-demand helicopter transportation in New York City and is planning to expand its service, e.g. to Los Angeles, where is a potential demand of UAM. According to the individual requirements, customers can either ask for the entire helicopter or for a seat on scheduled route within a city. Airbus developed its own on-demand helicopter concept, which has been successfully established in Sao Paulo [9] and has just been introduced in Mexico City [9]. Within this cooperation, Airbus collects valuable datasets (e.g. booking information) from Fly Blade, which is a prerequisite to develop new VTOL concepts explicitly for UAM demand. However, it is shown that additional understanding regarding demographics and requirements are needed [10].

Porsche Consulting investigates the market potential in 2035 for vertical mobility [4]. Within this study, which is based on a market model "grounded in today's mobility patterns and current market predictions", cities where grouped into five different clusters by their type (urban, suburban, and rural), income levels and some additional parameters. For each cluster one reference city was chosen and modelled (e.g. topography, mobility modes, mobility needs, traffic flows, and distribution of live-and-work patterns) to determine its future state. Based on this modelling approach, the VTOL service is expected to increase by 35 percent from 2025 to 2035 and requires 15,000 passenger vehicles worldwide. Intracity as well as intercity transportation has been taken into account, whereby the passenger demand for the intracity is expected to be twice larger than the demand between different cities. This demonstrates that the vertical mobility is a part of the urban mobility system, and not an individual conventional transportation mode. Moreover, the Asia Pacific regions were identified to offer the highest UAM potential (45\%), followed by Americas (30\%) and Europe and rest of the world (25\%). In this study vertical mobility has the primary function to connect other transport modes and it is not an "end-to-end"-mobility. It is expected that the system works only as a part of the modal split. in combination as only. This study shows only the percentage distribution in the regions, but not in specific areas [4].

In contrast to the aforementioned study, Uber Elevate considers UAM as a comprehensive transportation mode in the future which can substitute to the ground transportation between suburbs, cities and within cities. Uber demonstrates its mission as a radical mobility improvement and solution of urban mobility problems. In this study a potential vertiport infrastructure for UAM were identified in Los Angeles and London. A simulation for intracity passenger demand was performed based on historical data of former rides by Uber taxi service. The data is limited and include only distances of 20 to 120 miles, since only a few customer uses Uber for rides longer than 120 miles.

The literature review shows that UAM can be implemented within and between cities. To date, existing studies examine potential markets only for intra-cities as well as a regional split for UAM demand. However, there is a lack of studies which identify potential urban areas for UAM realization worldwide.

\section{B. Gravity Model}

The gravity model is based on the physical approach of Newton (1687) and it describes the strength between two bodies dependent on their masses and the distance between them. This approach was transferred to different fields where spatial interaction plays a major role, e.g. commuting-, trade- and travel flow but even to forecast air passenger demand between cities. As a simple gravity model is the most widely used model to predict the air passenger demand $P_{i j}$ between two cities $i$ and $j$ [16], it has been applied: 


$$
P_{i j}=k * \frac{\left(A_{i} A_{j}\right)^{a}}{d^{b}}
$$

where $A_{i}, A_{j}$ are the attractive factors of the cities, $\mathrm{d}$-is the distance between the cities and $a, b$ and $k$ coefficients of the variables, which enables the implementation of regression as well as statistical estimations.

Variables for the air passenger demand can be divided into two categories: geo-economic and service-related factors [11]. Usually the most significant factors are population, GDP, distance, GDP per capita, travel time, airfare and frequency [12]. In addition, further studies also consider income, buying power index, employment rate, size of aircraft andload factor [11], [13], [14], [15], [16], [17]. However, current studies are limited to specific regions, e.g. Europe and North America [16], [18], continents or countries, e.g. India, Turkey or USA [11], [12], [19]. The most global study was implemented for 279 cities worldwide without taking into account Africa and majority of Asia [20]. Thus, existing studies are hardly applicable to the world wide passenger demand forecast.

Due to this gap, an enhanced gravity model was developed within this study to forecast the passenger demand between various settlements worldwide and used to identify specific potential markets for the urban air mobility system implementation.

\section{Development of a global gravity model}

\section{A. Data}

In this study the dataset, which provides the basis of this study is provided by the German Aerospace Center (DLR). It was used within the "WeCare" Project [34] for the integrated modeling environment AIRCAST [21]. The major data were obtained from the ADI database, which provides the air passenger demand between airports [22] on yearly basis from 2002. Assuming the air passenger demand generation is in cities and not in airports, the passenger numbers between airports were aggregated to the city level.

The ADI database provides data for undirected demand: one connection includes passenger numbers from A to $\mathrm{B}$ as well as from B to A. In addition, this database provides the average airfare per connection per year. GDP, purchasing power parity (PPP) per country and global city population were taken from various databases [23], [24], [25]. The GDP PPP per city was obtained using country GDP PPP, country population and calculated GDP PPP per capita. All parameters (including airfare and GDP) were calculated in constant 2005 USD. The geographical coordinates of the cities were added to calculate the distance between them [26]. For countries in the database official languages [27], capital, and main touristic cities were added [28].

The base year in the study is 2012 with 4,435 cities worldwide and 533,170 air passenger demand connections between them. The same set of cities was considered for other available years. For this study data were available for the years $2002,2007,2011,2012$, and 2016, with 436,479 to 533,170 connections.

\section{B. Modeling}

This study demonstrates a forecast model based on analytical approaches from gravity models. The model uses a socio-economic scenario in order to determine the future air passenger demand. The following variables are taken into account based on existing studies and their availability. The dependent variable is:

- Passenger Demand $\left(P A X_{i j}\right)$ : The number of air passengers traveling between two cities are considered regardless the travel purpose (leisure or business), number of stops between origin and destination, as well as travel class (economy or business).

The independent variables are:

- Population $\left(P_{i j}\right)$ : Population has a direct effect on the size of the market, thus the population of both cities, Origin and Destination, are considered. The population of the cities was combined by taking the product of both populations.

- GDP $\left(B_{i j}\right)$ : GDP gives indication of economic profitability of a region as well as of income and wealth of the population in the cities. The GDP of the cities were combined by taking the product of both numbers.

- Ticket price $\left(T_{i j}\right)$ : Ticket price measures average actual travel price per connection.

- Distance $\left(D_{i j}\right)$ : Distance describes the spatial correlation between the cities. On longer distances air transportation has an advantage over other transport modes.

Binary variables are: 
- Language $\left(S_{i j}\right)$ : This binary variable investigates the cultural and language influence on air passenger demand. The variable is 1 , if the cities have the same language. Otherwise it is 0 .

- Capital $\left(\boldsymbol{H}_{\boldsymbol{i j}}\right)$ : The variable measures, whether it has a positive influence on air passenger demand, if one of them is a capital city of the country. Then it is 1 , otherwise 0 .

- Tourism-Attraction $\left(\boldsymbol{A}_{i j}\right)$ : This variable examines, whether tourism-attraction increase air passenger demand. It is 1 , if one or both cities have major attraction, otherwise it is 0 .

- Intercontinental $\left(\boldsymbol{I}_{\boldsymbol{i} \boldsymbol{j}}\right)$ : The Variable monitors, whether a connection is intercontinental. This variable simplified assumed, that between different regions no other transport mode exists, because of geographical positions (e.g. Oceans). It is 1 , when the cities are in the same regions, otherwise its 0 .

Therefore, the gravity model can be presented as follows:

$$
\ln P A X_{i j}=\beta_{0}+\beta_{1} \ln P_{i j}+\beta_{2} \ln B_{i j}+\beta_{3} \ln T_{i j}+\beta_{4} \ln D_{i j}+\beta_{5} S_{i j}+\beta_{6} H_{i j}+\beta_{7} A_{i j}+\beta_{8} I_{i j}+\varepsilon
$$

The estimation of the coefficients is conducted using the ordinary least square method for each available year. The results are shown in Table 1.

Table 1: Regression results

\begin{tabular}{lccccc}
\hline Coefficients & $\mathbf{2 0 0 2}$ & $\mathbf{2 0 0 7}$ & $\mathbf{2 0 1 1}$ & $\mathbf{2 0 1 2}$ & $\mathbf{2 0 1 6}$ \\
\hline \hline Konst. & $-6,58$ & $-9,61$ & $-9,6$ & $-10,21$ & $-6,73$ \\
$\mathbf{L n} \mathbf{B}_{\mathbf{i j}}$ & 0,43 & 0,47 & 0,47 & 0,47 & 0,41 \\
$\mathbf{L n} \mathbf{P}_{\mathbf{i j}}$ & - & - & - & - & - \\
$\mathbf{L n} \mathbf{T}_{\mathbf{i j}}$ & $-1,14$ & $-0,48$ & $-0,48$ & $-0,48$ & $-1,09$ \\
$\mathbf{L n} \mathbf{D}_{\mathbf{i j}}$ & $-0,30$ & $-0,68$ & $-0,67$ & $-0,68$ & $-0,34$ \\
$\mathbf{S}_{\mathbf{i j}}$ & 1,09 & 1,02 & 1,07 & 1,02 & 1,21 \\
$\mathbf{H}_{\mathbf{i j}}$ & - & - & - & - & - \\
$\mathbf{A}_{\mathbf{i j}}$ & 0,79 & 0,85 & 0,85 & 0,85 & 0,78 \\
$\mathbf{I}_{\mathbf{i j}}$ & - & - & - & - & - \\
\hline $\mathbf{R}^{2}$ & 0,33 & 0,31 & 0,30 & 0,30 & 0,33 \\
\hline $\boldsymbol{K}$ & 436.479 & 494.733 & 521.171 & 533.170 & 503.006 \\
\hline
\end{tabular}

All parameters are significant at $99 \%$ level. GDP, language, the tourism-attraction have a positive impact on the air passenger demand in contrast to the airfare and distance, which have a negative impact. The $\mathrm{R}^{2}$ obtained is 0.30 0.33 . The regressions of 2012 and 2016 show the highest $\mathbf{R}^{2}$. Since the data for the year 2016 include more connections it is chosen as the basis model. In order to validate the developed model, the air passenger demand is forecasted from the year 2016 to 2012 and compared with the real air passenger volume from 2012. The examined differences between the real and forecasted air passenger demand are classified into defined ranges [29], [30]. The accuracy of the forecast is measured regarding the ranges, e.g. the examined difference of air passenger demand is in a defined range of $\pm x$ passenger. The forecast is correct, when the difference is within the defined range. The higher the passenger volume in small, sufficient ranges the better the accuracy of the forecast will be. The results of the validation showed that the model demonstrates high accuracy in the range of \pm 300 passenger, where passenger number was forecasted correctly for $82 \%$ of the connections $(\mathrm{K}=421.456)$. The differences between the real and forecasted passenger numbers are $-1.1 \%$, thus the forecast shows precise results. However the passenger number on correctly predicted connections is only ca. $1 \%$ of the total passenger number. Thus is can be concluded that the developed gravity model obtained sufficient forecasts for connections with a relatively small passenger demand.

The gravity model allows forecasting air passenger demand between cities all over the world. Moreover the presented model can be used in in various applications including demand assessments of innovative concepts in aviation.

\section{Model application: Forecasting air passenger demand for 2042}

The developed gravity model is an econometric model, which shows the correlation between the dependent and its independent variables. The model application for the air passenger demand prediction requires socio-economic data for future development prognoses. 
With respect to the increased interest to urban air mobility the validated model was applied to determine potential markets for UAM services with connections shorter than $300 \mathrm{~km}$. Using additional assumptions, an analysis for urban air mobility to determine promising future innovative urban transportation operations was conducted.

\section{Data}

The socio-economic data were obtained from the Global Environment Outlook (GEO-4) Scenarios of the United Nations Environment Programme for the year 2042. There are four different scenarios, however for this study the Sustainability First scenario is used as a middle one among others. Socio-economic data are GDP and population on country-level which were transform to a city-level [30]. For modelling average ticket price, a simplified model was adopted from [30] which takes into account the distance between cities and the average oil price.

In addition, information regarding official languages, capitals, intercontinental connections, and tourismattractions were added. For tourism-attraction cities it is assumed, that they will not change within the years. Using the obtained data and described models the simulation to 2042 was conducted.

\section{Results}

In order to forecast the air passenger demand for 2042, the validated model (Eq. 4) is applied to the described datasets.

$$
\ln P A X_{i j}=-6,73+0,41 \ln B_{i j}-1,09 \ln T_{i j}-0,34 \ln D_{i j}+1,21 S_{i j}+0,78 A_{i j}
$$

The forecasted air passenger demand for 2042 is shown in Fig. 1.

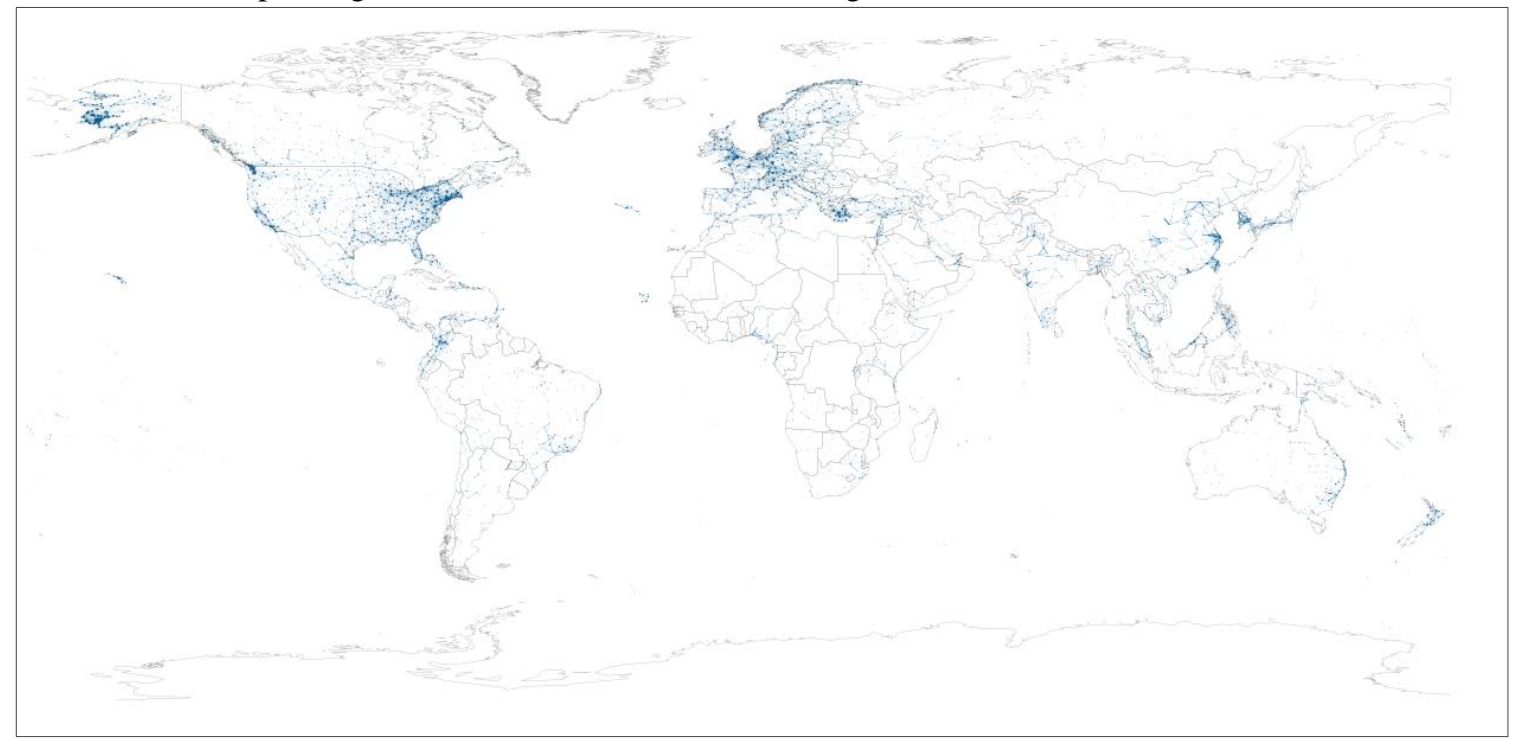

Fig. 1: Forecasted air passenger demand for distances up to $300 \mathrm{~km}$ in the year 2042

It can be seen, that the passenger demand congests in some areas, particularly in North America, in Europe and in some parts of Asia, but also in South America, Africa, and Oceania. A detailed view of notable regions is presented in Fig. 2.



A: New York City

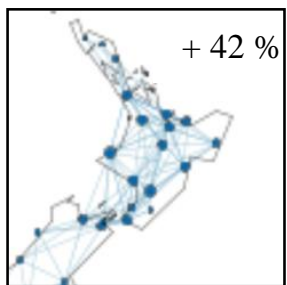

B: Auckland



C: Shanghai

Fig. 2: Forecasted air passenger demand in 2042 
Figure 2 shows areas which are potentially markets for urban air mobility the passenger demand growth rates in comparison to the air passenger demand in 2016.

New York City (Fig.2a) shows the busiest demand, likely because of its large population and its relevance as an important economic city. The forecast shows a high air passenger demand in Shanghai (Fig.2c) and its surroundings. Shanghai shows a rapid of air transportation development and economic growth. Moreover in Oceania a high air passenger demand can be noted in Auckland (Fig.2b).

Tab.2 demonstrates 28 potential markets which were identified based on the air passenger demand. The main growth occurs in the following cities and surroundings:

Tab.2: Cities and surroundings with high density of air passenger demand

\begin{tabular}{lllllll}
\hline North America & South America & Europe & Africa & Middle East & Asia & Oceania \\
\hline Vancouver & Bogota (c) & London (c) & Lagos & Istanbul & Lahore & Sydney \\
Seattle & Sao Paulo (c) & Brussels (c) & & Dubai & Mumbai & Auckland \\
San Francisco & & Zürich & & & Dhaka (c) & Singapore (c) \\
Los Angeles & & Paris (c) & & & Shanghai \\
Chicago & & Milan & & & Seoul \\
New York City & & Athens (c) & & & Hong Kong \\
Miami & & & & Chongqing \\
& & & & & \\
\hline
\end{tabular}

c: capital

Tab.2 demonstrates the high-frequented notable areas.. Some of the cities are capitals of the respective countries and play a major role as important economic and financial centers of their countries. The other listed cities are metropolitan areas and of extreme importance.

\section{Analysis of potential markets for inter-urban mobility}

\section{E. Assumptions}

In order to assess potential markets for interurban air mobility, additional assumptions are required. It is assumed that urban air mobility can be implemented in cities and their surroundings with:

- Large population: A high population density implicates a high mobility demand and it is expected that there is a high probability that some people would use UAM. On the other hand it is assumed that a large population challenges the urban infrastructure capacity saturation, such as traffic jams, gridlocks, etc. Studies show that this situation plays a major role in Megacities [3]. A megacities is a citie with more than 10 million inhabitants. Therefore it is assumed that population more than 10 million people in 2042 is a market for UAM. .

- Limited urban mobility: For cities where urban transport systems are close to capacity limits, it is presumed that radical changes are needed because capabilities to optimize urban mobility on ground transportation are restricted. Therefore it is assumed to have a high potential for UAM. This assumption was measured based on an existing study [2]. The study demonstrates a rating and shows that the most considered cities need urgent changes due to upcoming transportation capacity limits. Using these results, cities are assessed as insufficient study if their index is within the average range or smaller (75).

- Economic City: UAM is assumed to be relevant for economic cities because of commerce and business meetings, which are more time-than price sensitive. Therefore UAM could be affordable and convenient. A city is assigned to this assumption, if the GDP per capita is higher than 40,000 USD in 2042. This value is determined explorative.

- Passenger Demand: UAM might be of importance for cities for connections where the air passenger demand is especially high, assuming that a fraction of those passengers are time sensitive or rather be in a hurry to get to the respective destination. Thus these passengers would change from regular air transport to UAM. The air passenger demand will be ranked as high in this study if the forecasted demand is higher than 100,000 passengers. In this study it is simplified assumed that 100,000 passengers a year per city-pair may correspond two connections per day. Thus a high-frequented connection is assumed.

\section{F. Results}

Taking into account specified assumptions cities from Tab. 2 are assessed by their population, GDP, their air passenger demand in the year 2042 and their current situation of urban mobility systems. The results of this analysis are shown in Fig.3. 


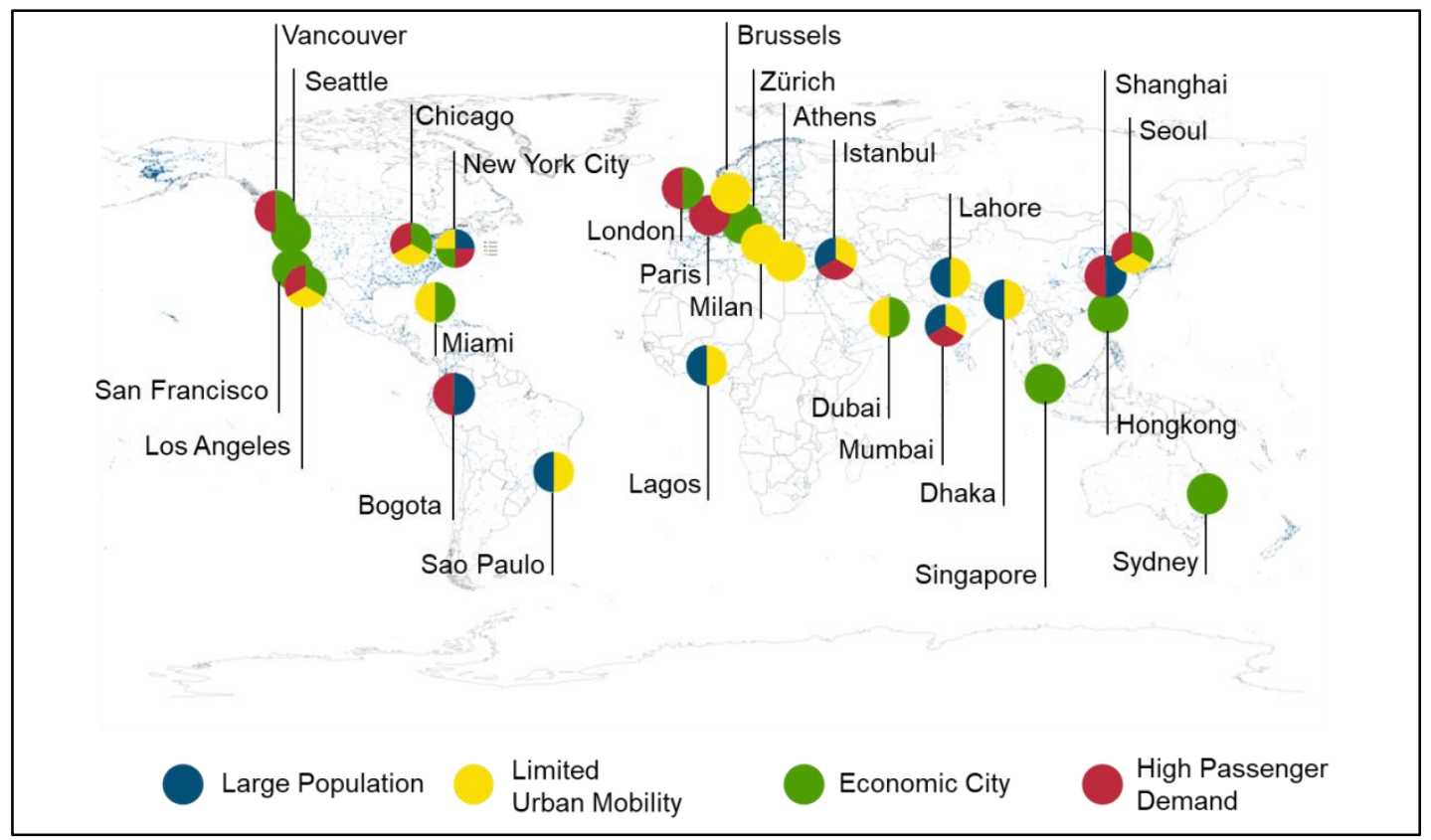

Fig. 3: Potential markets for interurban air mobility

Figure 3 demonstrates 26 potential markets for interurban air mobility system. The highest numbers of markets are in North America, Europe, and Asia, but also in South America, Africa and Australia. Figure 3 shows that UAM can be implemented for different based on different criteria. For example, some cities are single-colored (e.g. Seattle, Brussels, and Paris etc.). This means that based on their characteristics, these cities were assigned only to one of the aforementioned assumptions. Other cities are shown with circles with two (e.g. Vancouver), three (e.g. Los Angeles) or four colors (e.g. New York), which mean they fulfill more than one assumption. By comparing the identified cities (Tab. 2) and the potential markets (Fig. 3) it should be noted that, Chongqing and Auckland are not considered as potential markets. This is because these cities could do not meet the aforementioned assumptions.

Based on the analysis, two groups of air passenger demand can be defined. The cities in the first group have a high level of income (green). It is assumed that business is active in these cities, people have a high living standard and, therefore, these cities have a high number of potential users. Here, UAM would not primarily mean a discharge for urban traffic, but would rather be an innovative transport mode. Based on this analysis Seattle, Singapore, Hong Kong, and Sydney belong to this category.

The cities in the second group are about to reach their transport capacity limits and characterized by traffic congestions (yellow). People have long commuting times. Therefore the quality of living is constrained. In this case, an action is urgently needed in order to support the urban mobility. In this category Brussels, Milan, and Athens were identified.

In general, cities can be assigned to more categories (see Fig. 1). Especially cities in mentioned categories (yellow and green) have a high potential for implementing UAM. Here Miami and Dubai can be recognized.

In addition, cities with the combination of high wealth as well as high air passenger demand (green and red) show extraordinary potential. The demand for air transportation on distances up to $300 \mathrm{~km}$ is high and rich cities may have large number of business people. Thus, the air passenger demand for UAM in these cities may exist, because of flexible, fast, and on-demand transportation which can be offered by UAM. Vancouver and London were identified for this group.

It can be seen in Fig. 2, that cities which can be assigned to the three mentioned assumptions (yellow, green, and red) have a remarkable potential for UAM. These cities have economic centers with a high income level. Their current urban mobility systems are about to collapse and a large number of people is travelling on distances up to $300 \mathrm{~km}$ by air transportation. In these areas the willingness to travel on short distances exists. As the result, Los Angeles, Chicago, and Seoul were highlighted.

It is expected that cities with a large population in future will have a need for UAM because of the traffic congestion and therefore, the passenger demand. The analysis shows that there are no cities which belong only to 
that category, but in combination with high passenger demand (red and blue). This underlines the assumptions, that people in these cities have travel necessities on short distances and possibly will use UAM, because it is convenient and comfortable. In this study it is Bogota and Shanghai.

Moreover the combination of large population and collapsing traffic is found (yellow and blue). The urgency of action is clear and includes cities such as Sao Paulo, Lagos, Lahore, and Dhaka.

Fig. 2 shows potential markets which meets the requirements for large population, high passenger demand and limited urban mobility system (blue, yellow, and red). Here the need for action is also urgent and UAM might be the solution for Istanbul and Mumbai.

However, it is assumed that the major potential has a city which belongs to all four assumptions (red, yellow, blue and green). An economic city has a remarkable number of inhabitants with a high income level and travel distances up to $300 \mathrm{~km}$. New York City meets all this requirements and can be highlighted as the largest potential market for UAM in the year 2042.

The ranking of the potential markets of this study can be found in Fig. 4.

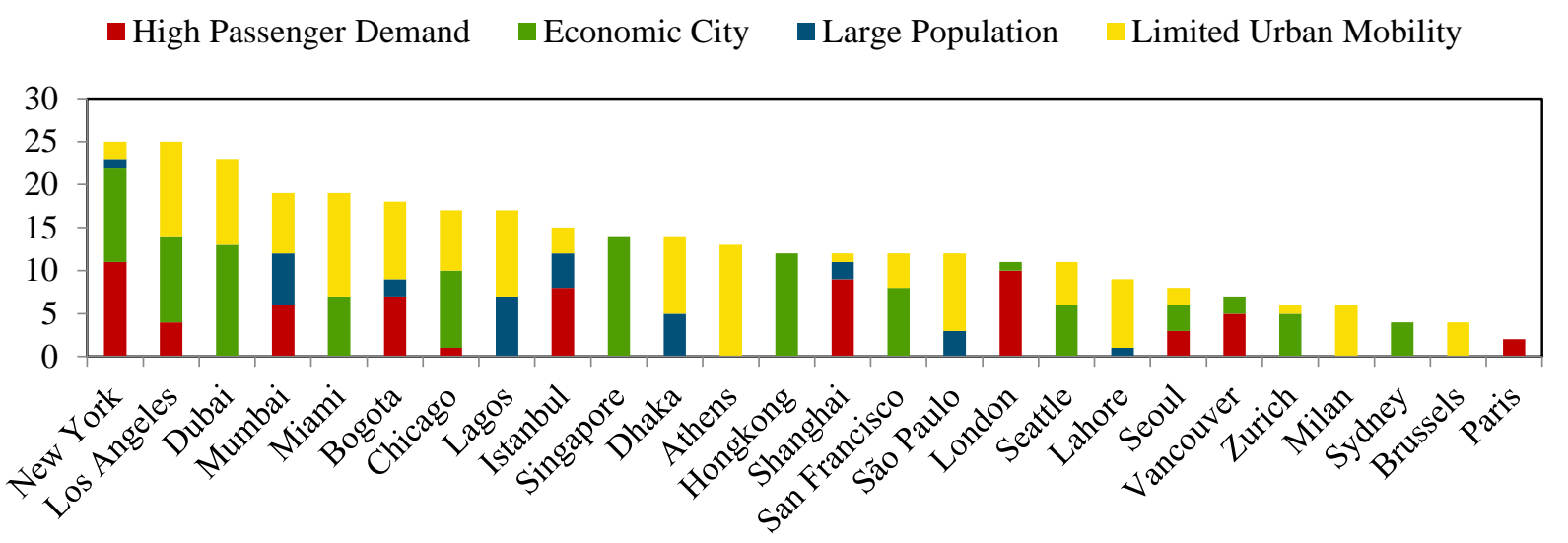

Fig. 4: Ranking of the potential UAM markets

The cities were assigned to the categories by assumptions (see G. Assumptions). To rank the potential markets the Borda Count Method was used [32]. This multicriterial method assigns scores to the cities based on the. All cities, which meet the individual requirements, were ordered downwards in respect to this assumption. The city on the last place received 1 point, the second last 2 points etc. This vote was conducted for all four assumptions. In the end the values were summarized. Consequently, the city with the highest score has the highest potential.

Obtained results show a plausible trend for urban air mobility since they are in line with previous studies. For example London and Los Angeles were already identified to have a high potential [3] and Blade Fly plans to launch their air taxi service in Los Angeles [10]. In Sao Paulo air taxis were already applied in 1999 to discharge the urban transportation which supports our results [9]. In addition, it is discussed to launch the UAM service in Dubai [33] which goes along with the results of our study.

This study provides an understanding of how the interurban air mobility market will possibly look like in the future and shows potential areas to implement the UAM concept. The results of this study can be used for further research in order to identify, for example, the future number of VTOL for particular area, the number of seats in a VTOL, infrastructure configuration and vertiport spatial distribution.

Furthermore this study can be combined with further studies, which investigated intra-urban air mobility. This combination would allow an overall overview of UAM demand and offers the possibility to make this analysis more precise. By including further knowledge about potential users, general acceptance or information about ticket prices, the analysis could be more robust. In general this analysis is an important base for the overview on the UAM development.

\section{Conclusion}

This paper identifies potential markets for interurban air mobility in 2042 based on the developed gravity model which forecasts the air passenger demand between settlements $(N=4435)$ worldwide. Based on socio-economic factors the air passenger demand was forecasted to 2042. In order to identify potential UAM markets maximum range was limited to $300 \mathrm{~km}$ and additional assumptions were defined, such as large population, urban mobility systems close to break down, high income cities and especially cities with a high passenger demand. Some of the 
identified cities were assigned only to one, others to more assumptions, which underline the need of UAM. Thus, 26 interurban potential markets were identified in America, Europa, Africa, Asia, and Oceania. Due to the assumptions it can be seen that some cities have a high potential for UAM in order to reduce the urban transportation collapse, while other settlements could implement UAM as additional piece of transportation system.

The results of this study offer a general overview of the different potential markets of UAM. To complete the future potential UAM markets assessment for interurban as well as for intra-urban air mobility the study can be combined with further studies, e.g. Uber Elevate. More precise results regarding potential markets can be reached by implementing additional requirements of potential customers or information regarding costs.

\section{References}

[1] United Nations, Departement of Economic and Social Affairs, Population Division. 2015. "World Urbanization Prospects: The 2014 Revision." https://esa.un.org/unpd/wup/Publications/Files/WUP2014Report.pdf.

[2] Lerner, Wilhlem. 2011. "The Future of Urban Mobility-Towards Networked, Multimodal Cities of 2050." Arthur D Little Future Lab, no. No. 1: Future of Urban Mobility. http://www.micromillenniumusa.com/files/DocPublishing/Future_of_urban_mobility.pdf.

[3] Holden, Jeff, and Goel Nikhil. 2016. "Fast-Forwarding to a Future of On-Demand Urban Air Transportation."

[4] Grandl, Gregor, Jan Cachay, Han Ross, John Salib, Martin Ostgathe, and Stefan Doppler. 2018. "The Future of Vertical Mobility Sizing the Market for Passenger, Inspection, and Goods Services until 2035." Porsche Consulting. https://fedotov.co/wp-content/uploads/2018/03/Future-of-Vertical-Mobility.pdf.

[5] Audenhove, François-Joseph Van, Laurent Dauby, Oleksii Korniichuk, and Jérôme Pourbaix. 2014. "The Future of Urban Mobility 2.0." http://www.uitp.org/sites/default/files/members/140124 Arthur D. Little \%26 UITP_Future of Urban Mobility 2 0_Full study.pdf.

[6] Federal Ministry for Economic Cooperation and Development. 2016. "Urban mobility strategy for liveable cities", p.8.

[7] “Vahana.” 2018. Accessed April 11. https://www.airbus-sv.com/projects/1.

[8] aero. 2018. "Embraer Und Uber Planen Fliegende Taxis." Accessed April 11. http://www.aero.de/news28187/Embraer-und-Uber-planen-fliegende-Taxis-bis-2024-.html.

[9] Voom. 2018. "Voom - On-Demand Helicopter Service." https://www.voom.flights/.

[10] Head, Elan. 2018. "Airbus, Blade See Growing Future for Urban Air Transport - Vertical Magazine." https://www.verticalmag.com/news/airbus-blade-see-growing-future-urban-air-transport/.

[11] Rengaraju, V. R., and V. Thamizh Arasan. 1992. "Modeling for Air Travel Demand." Journal of Transportation Engineering 118 (3): 371-80.

[12] Sivrikaya, Orhan, and Enar Tunç. 2013. "Demand Forecasting for Domestic Air Transportation in Turkey." The Open Transportation Journal 7: 20-26. https://www.okan.edu.tr/uploads/pages/ogrencilerimizin-ulusalve-uluslararasi-akademik-yayinlari/Sivrikaya_TOTJ.pdf.

[13] Alam, Jobair Bin, and Dewan Masud Karim. 1998. "Air Travel Demand Model for Domestic Air Transportation in Bangladesh." Journal of Civil Engineering 26 (1): 1-13. http://www.jceieb.org/pdfdown/ce260101.pdf.

[14] Ba-Fail Seraj Y Abed, Abdullah O, Sajjad M Jasimuddin Jeddah, and Saudi Arabia. 2000. "The Determinants of Domestic Air Travel Demand in the Kingdom of Saudi Arabia." Journal of Air Transportation World Wide 
5 (2): 72-86. http://citeseerx.ist.psu.edu/viewdoc/download?doi=10.1.1.564.8400\&rep=rep1\&type=pdf.

[15] Carson, Richard T, Tolga Cenesizoglu, and Roger Parker. 2011. "Aggregate Demand for US Commercial Air Travel." International Journal of Forecasting 27: 923-41.

[16] Grosche, Tobias, Franz Rothlauf, and Armin Heinzl. 2007. "Gravity Models for Airline Passenger Volume Estimation." Journal of Air Transport Management 13 (4): 175-83.

[17] Jorge-Calderón, J.D. 1997. "A Demand Model for Scheduled Airline Services on International European Routes." Journal of Air Transport Management 3 (1): 23-35.

[18] Hazledine, Tim. 2009. "Border Effects for Domestic and International Canadian Passenger Air Travel." Journal of Air Transport Management 15 (1): 7-13.

[19] Bhadra, Dipasis, and Jacqueline Kee. 2008. "Structure and Dynamics of the Core US Air Travel Markets: A Basic Empirical Analysis of Domestic Passenger Demand." Journal of Air Transport Management 14: 27-39. doi:10.1016/j.jairtraman.2007.11.001.

[20] Doucet, Romain, Paula Margaretic, Christine Thomas-Agnan, and Quentin Villotta. 2014. "Spatial Dependence in (Origin-Destination) Air Passenger Flows." Papers in Regional Science 96 (2): 357-80.

[21] Ghosh, Robin, Katrin Kölker, and Ivan Terekhov. 2015. "Future Passenger Air Traffic Modelling: A Theoretical Concept to Integrate Quality of Travel, Cost of Travel and Capacity Constraints."

[22] Sabre Airline Solutions. 2017. “Aviation Data Intelligence." Accessed December 11. https://www.sabreairlinesolutions.com/home/software_solutions/airports/.

[23] MaxMind. 2017. "Free World Cities Database." Accessed December 11. https://www.maxmind.com/de/freeworld-cities-database?pkit_lang=de.

[24] The World Bank. 2017. "World Bank Open Data." Accessed December 11. https://data.worldbank.org/.

[25] United Nations. 2017. "National Accounts Main Aggregates Database." Accessed December 11. https://unstats.un.org/unsd/snaama/Introduction.asp.

[26] OpenFlights. 2017. "Airport, Airline and Route Data." Accessed December 11. https://openflights.org/data.html.

[27] Auswärtiges Amt. 2018. “Länderinformationen.” Accessed January 29. https://www.auswaertigesamt.de/de/aussenpolitik/laender.

[28] Google.Destination. 2018. "Reiseführer.” Accessed January 30. https://www.google.de/destination.

[29] Law, Rob, and Norman Au. 1999. "A Neural Network Model to Forecast Japanese Demand for Travel to Hong Kong." Tourism Management 20: 89-97. http://ac.els-cdn.com/S0261517798000946/1-s2.0S0261517798000946-main.pdf?_tid=94b53b30-88dd-11e7-a40e00000aab0f6c\&acdnat=1503587273_d2a58e06d4e8a766e9299c99a45aaf14.

[30] Terekhov, Ivan. 2017. "Forecasting Air Passenger Demand between Settlements Worldwide Based on SocioEconomic Scenarios."

[31] Lilium. 2018. "Lilium | Electric Vertical Take-Off and Landing Jet." https://lilium.com/.

[32] Vavríková, Lucia. 2011. "Multicriteria Decision Making and Rankings Based on Aggregation Operators (Application on Assessment of Public Universities and Their Faculties).” Acta Polytechnica Hungarica 8 (3). 
https://www.uni-obuda.hu/journal/Vavrikova_29.pdf.

[33] Volocopter. 2018. "Volocopter - Home." https://www.volocopter.com/de/.

[34] Volker Grewe, Katrin Dahlmann, Jan Flink, Christine Frömming, Robin Ghosh, Klaus Gierens, Romy Heller, Johannes Hendricks, Patrick Jöckel, Stefan Kaufmann, Katrin Kölker, Florian Linke, Tanja Luchkova, Benjamin Lührs, Jesper van Manen, Sigrun Matthes, Andreas Minikin, Malte Niklaß, Martin Plohr, Mattia Righi, Simon Rosanka, Angela Schmitt, Ulrich Schumann, Ivan Terekhov, Simon Unterstrasser, Margarita Vázquez-Navarro, Christiane Voigt, Kai Wicke, Hiroshi Yamashita, Andreas Zahn and Helmut Ziereis. 2017. "Mitigating the Climate Impact from Aviation: Achievements and Results of the DLR WeCare Project". Aerospace 2017, 4, 34; doi:10.3390/aerospace4030034 